\title{
101
}

\section{The Networking of School Systems: Can IT Improve Teaching and Learning?}

\author{
Chair: Anne McDougall (AU) \\ Panel: Pam Bishop (AU), Lynne Schrum (US), Geoff Romeo (AU), Greg \\ Baker (AU), Bert Moonen (NL)
}

Keywords: teaching methods, innovation, curriculum development, collaborative learning

Geoff Romeo described the support for ICT in schools in the state government school system in Victoria, Australia. A network, VicOne, links all government departments in the state; its largest user is the Department of Employment, Education and Training. Services provided by this network include an electronic mail system called EduMail; a very popular web site titled SofWeb which connects schools to global classroom projects, software and other resources, and discussion groups; professional development materials, and information from the state's so-called navigator schools where innovative activities involving learning technologies are undertaken.

Pam Bishop outlined features of the network CEVN, developed in Victoria for the Catholic education system in that state. This network was established late in 1998, and all the schools were connected by the end of 1999 , with funding provided for a computing support staff member for each school. The aims of the project included provision of global communication and cheaper, faster and safer Internet access for students, development of a learning plan in each school, use of the local area network for classroom management, curriculum planning and development, and monitoring and reporting of student progress. A monthly newsletter is distributed to all schools. Ongoing financial support is needed for the project, and professional development for teachers, administrators, and principals is a critical issue to be addressed. 
Greg Baker, also from Victoria, described initiatives being taken to build an on-line community associated with a non-government independent P-12 school. All the school's curriculum resources have been put onto an intranet available from both the school and the students' homes, with a view to encouraging home-school links and so-called anywhere anytime learning. Staff at the school is required to provide all curriculum materials - including homework, notices, etc. - on the intranet. Each staff member and each student has a personalised login to the system. Staff and senior students in the school are required to have portable notebook computers, and the school provides wireless networking for these machines as well as the regular backbone. The initiative is supported by a strong professional development program. Benefits of the project include improved access and better homeschool links. Challenges have been associated with provision of technical support, security, system integration, and funding.

An international perspective was provided by Bert Moonen and Lynne Schrum. Bert Moonen described an Internet based wide area network or 'knowledge net' established in the Netherlands, a network to which all schools are to be connected by the end of 2001. The benefits include faster access, personal e-mail addresses for teachers and students, educational resources available on a supervised and secure part of the Internet, discussion groups, and connection for libraries, museums and publishers. The main problems were with reliability (early in the project) and the connection of local area networks to the wider area network.

Lynne Schrum at the University of Georgia is working with schools looking to use networking. Perceived benefits here include increased communication possibilities, relief from isolation, and enhanced professional development opportunities with on-line materials. The challenges faced have concerned security of information, privacy, the development of acceptable use policies, equity issues, and the problem of teachers being expected to be available 24 hours a day and 7 days a week. 